\title{
DIE GESKIEDENIS VAN DIE TEOLOGIESE SKOOL.
}

(Met besondere verwysing na die betekenis van die eerste professore).

DIE BEGIN.

Direk na die totstandkoming van 'n kerk word die behoefte aan 'n eie inrigting vir die opleiding van bedienare van die Woord gevoel. Dit kan ook nie anders nie. Hoe kan 'n kerk bestaan as daar geen predikers van die Evangelie is nie? Die vaders het met hul fyne voelhorings ook goed besef dat leraars van oorsee wel die eerste stoot kan gee, maar dat dit tog uiteindelik sover moet kom dat die seuns van die land tot predikers opgelei word. Het die bewoners van die noordellke distrikte van Kaap- 
land dan nie aan den lijve ondervind wat dit beteken as hul leraars nóg nasionaal nóg konfessioneel met hulle kan saamvoel nie?

Geen wonder dan ook dat ds. D. Postma, stigter van die Gereformeerde Kerk, as sy eerw. in 1866 aan sy gemeente meedeel dat hy die beroep na Burgersdorp aangeneem het terwille van die opleiding, daarop laat volg: „De opleiding acht ik de allernoodigste zaak voor onze gemeenten bij hare steeds toenemende uitbreiding. Zoo zoude ik dan wel niet meer in dit land wandelen in de bediening van herder en leeraar maar evenwel voor u blijven werken in die allernoodigste en allerbelangrijkste zaak" (kursivering van ds. Postma; aangehaal in Almanak Geref. Kerk, 1939).

Reeds op die heel eerste sinode (1862) word die saak ter sprake gebring. Ds. Postma het 'n geskiedkundige oorsig gegee oor die opleiding van predikante, sowel uit die Ou en Nuwe Testament as uit die latere Kerkgeskiedenis, en sommige kerkrade het reeds hier hul verlange na 'n eie Teologiese Skool te kenne gegee.

Die saak word uitgestel tot op die sinode van 1863 en tydens hierdie vergadering lê ds. Postma 'n geskrewe stuk voor, waarin ernstig daarop aangedring word dat voorsiening gemaak sal word vir 'n kerklike opleiding van aanstaande predikante. Die kerk moet hom hierin nie afhanklik voel of afhanklik maak van die wêreldlike owerheid nie en nog veel minder van vreemde invloed.

Hoofsaaklik weens gebrek aan die nodige fondse kon hierdie sinode nie tot die oprigting van die Skool oorgaan nie, maar besluit dat die leraars voorlopig die opleiding ter hand moet neem. Vrug van hierdie arbeid was die feit dat reeds op die sinode van 1866 kandidate geeksamineer kon word.

Nadat ds. Postma in 1866 die beroep na Burgersdorp aangeneem het, kon sy eerw. meer rustige tyd aan studie wy. Hierdie jaar kan dan ook as die beginjaar van die opleiding van leraars van die Geref. Kerk aangemerk word, hoewel die Skool nog nie formeel opgerig was nie.

OPRIGTING VAN DIE SKOOL.

Vóór die sinode van 1869 het ds. Postma 'n kragtige aksie in Kaapland op tou gesit eri self die inisiatief geneem met die insameling van fondse in die vorm van rentelose aandele. Op die sinode kom Burgersdorp dan met 'n voorstel dat die inrigting wat deur die kerkraad onder leiding van die leraar daargestel is, slegs uitgebrei sal word deur die beroeping van 'n tweede leraar vir Burgersdorp, onder voorwaarde dat die ander gemeentes vir sy traktement sal bydra.

Die voorstel is deur die sinode aanvaar en sodoende is ds. Postma aangewys as die ecrste dosent. Ds. J. Lion Cachet, die pasverkose tweede 
leraar van Burgersdorp, het as tweede dosent opgetree. Op 29 November 1869 is die Skool feestelik geopen.

By die totstandkoming van die inrigting tref verskillende sake ons: Ten eerste die nadruk wat gelê word op die feit dat die kerk self die opleiding van sy bedienare van die Woord ter hand moet neem. Ten tweede dat die Skool van die begin af op streng konfessionele standpunt gestaan het.

Ten derde dat nadruk gelê is op die wetenskaplike vorming van die aanstaande leraars.

Ten vierde dat die nasionale karakter van die Skool beklemtoon is.

Oor elkeen van hierdie aspekte word in ander artikels gehandel, sodat ons daaroor nie verder hoef uit te wei nie. Slegs by die eerste punt wil ons ietwat langer stilstaan, want dit geld hier 'n belangrike beginsel, waarvoor die Gereformeerdes sware offers gebring het. Gedurende die 75 jaar is baie duisende van ponde deur die Kerk byeengebring vir hierdie saak, waar dit miskien vir 'n geringe som van sy kant sy Bedienaars van die Woord aan een of ander universiteit kon laat oplei het. In die Nederlande, vanwaar ds. Postma gekom het, is die opleiding van leraars deur die teologiese fakulteite van die universiteite behartig. Die kerke het egter oor die opleiding weinig of geen seggenskap gehad nie en die vaders van die Afskeiding van 1834 het besef dat onder hierdie omstandighede geen waarborg bestaan dat die dwaalleer nie sal insluip nie. Vandaar dat hulle oorgegaan het tot die oprigting van 'n eie Teologiese Skool. Geen wonder dus dat ds. Postma, 'n geesteskind van die Afskeiding, dadelik beklemtoon het: opleiding vir die kerk deur die kerk. Uit hierdie beginsel is die Teologiese Skool gebore en dit sou ontrou teenoor die nagedagtenis van die stigters wees as die Skool van die Kerk prysgegee word.

Aan die ander kant wou die stigters van die Skool hulself ook nie in 'n hoek terugtrek nie. Van die begin af is die gedagte uitgespreek dat aan die Skool ook jongelinge moet kan studeer sonder dat hulle juis die predikantsamp op die oog het. M.a.w. die voorbereidende afdeling het die kieme van 'n latere universiteit bevat-'n universiteit wat met Skool en Kerk ten nouste verbonde sal wees. Die ideaal is verwesenlik in die P.U.K. vir C.H.O. wat in 1921 selfstandig geword het. Die Sinodes van 1936, 1939 en 1942 was dan ook heeltemal in die historiese lyn toe hulle aangedring het op 'n behoorlike geskrewe ooreenkoms tussen die twee inrigtinge. Vanself sal die Teologiese Skool die meeste belangstel in die Teologiese Fakulteit, aangesien die Kerk ook'n roeping het teenoor die teologiese wetenskap, afgesien van sy eie opleiding van Bedienare van die Woord. Maar die Kerk stel ook intens belang in die prinsipiële opleiding van sy lidmate oor die hele gebied van die wetenskap. Met die opening 
van die Teologiese Skool op Potchefstroom in 1905 getuig ds. P. Postma, voorsitter van die Kuratorium, as volg: „De stichter der Kerk voelde dadelijk de behoefte van een litterarisch departement naast het theologische. Het gereformeerd beginsel moet heel de wetenschap beheerschen en bevruchten. Onze jonge mannen die in andere vakken dan de theologische studeeren moeten onder invloed van dat beginsel opgeleid worden, anders zijn zij voor de Kerk verloren. Spreker had er ondervinding van. Hij studeerde Letteren en Matheses in een vreemde omgeving en niet onder bezieling en besturing van de Gereformeerde grondgedachte. Vandaar dat hij hiar den mensch gesproken voor de Kcrk verloren was en eerst wonderlijk door God moest teruggeleid worden."

\section{DIE LERSTE DOSENTE.}

Aangesien die eerste twee dosente soveel jare aan die Skoul verbind wals, is dit paslik dat by hul persone en hul wetenskaplike prestasie ietwat langer stilgestaan word. Dit sal naamlik deur iedereen erken moet word dat die oorspronklike stigters van 'n inrigting tot 'n baie groot mate hul stempel op die stigting afdruk.

1. PROF. D. POSTMA.

Eers die karakteristieke eienskappe van sy persoonlikheid. Selfs sy teenstanders moes erken dat hy 'n man van diepe godsvrug was en mitsdien 'n persoonlikheid. Waar nodig kon hy beslis optree en as hy oortuig van sy saak was, kon hy taaie deursettingsvermoë aan die dag lê. Tog het hy altyd kalm en waardig gebly en die respek van iedereen afgedwing. Ds. McCormack, N.G. predikant te Burgersdorp, getuig by die begrafnis van prof. D. Postma as volg: „A powerlul intellect, a strong will and a vigorous physical vitality furnished him with all the qualities requisite to act upon and influence others; his activity knew no pause. The work he accomplished was marvellous .... The great prevailing motive of his life was the entire dedication of himself, of every power and faculty to the service of that beloved Master who loved him and gave Himself for him." (Burgersdorp Gazette, Jan. 8, 1891).

'n Besondere kemmerk viln prof. Postma was ook sy akkuraatheid en presiesheid. Dieselfde leraar verklaar van hom: ,Of him it can be truly said: he has finished his work and at his death all his matters were found in the best possible order. During his life everything was kept in such perfect order that he could at any time leave everything behind ..." (Ibidem).

Ds. W. H. Gispen, jnr. skryf in die ,Maandblad van de Geref. Kerk te Zwolle" (d.d. Mei 1912) aangaande sy bediening: „De tijd van ds. Postma was een tijd van vele regelingen. Het blijkt wel dat hij gaarne goede orde in kerkelijke zaken had. Hij was ongetwijfeld een man van 
kunde en bekwaamheid." Aangaande sy preekgawe sê die vader van wyle dr. Kestell die volgende: „Ds. Postma is een van die beste predikers wat ek gehoor het. Dit lyk of hy tuis is in die preekstoel en of hy 'n welbehae het in (to delight in) die.prediking ... ek het alle rede on te glo dat hy 'n goeie en waarlik godvrugtige man is." (Uittreksel uit die dagboek van mnr. Kestell). Die volgende woorde van ds. P. Huet, predikant by dic N.G. Kerk in Natal is bekend, maar moet tog by hierdie feesgeleentheid weer in herinnering gebring word: „Ik geloof dat ds. Postma alle aanspraak heeft op de achting en liefde van alie godvruchtigen. Zoo waardig een Evangeliedienaar, dat ik als den grootsten zegen zoude achten, zoo al onze gemeenten met dergelijke leeraren bevoorrecht werden. Er is niet veel geestelijk onderscheidingsvermogen toe noodig on het 'wij dan hebben den zin van Christus' in al's mans gedragingen, woorden, schriften te lezen. Ik geloof dat hij op zijnen weg, ook in de zaak der Afscheiding, door Eenen geleidt wordt tegen wien het vergeefs en vreeselijk is uit verkeerden ijver te strijden, en omtrent wien het hoog tijd wordt, hem niet langer te bekampen, noch als scheurmaker te qualificeren, en daarentegen zijne belasteraars aan de kaak te stellen."

Hoewel hy weens gebrek aan finansiële middele 'n groot deel van sy studie privaat moes doen, naas sy gewone ambag, en hoewel die teologiese opleiding in die Christelik-Afgeskeie Kerk van Nederland nog maar in sy beginstadium was, het vader Postma dit ver gebring. Hy was deeglik deurkneed in die teologiese vakke en het daarby 'n besonder goeie kennis van die grondtale van die Skrif gehad. O.m. het hy ook Aramees, Siries en Arabies geken. En tog was hy altyd baie beskeie.

As hy in 1869 as professor theologicus gekies word, verklaar hy o.m.: „Uwe keus op mij tot één der onderwijzers aan de Theologische School ontzet mij, bij de beseffing van hetgeen daaraan verbonden is en met het oog op mij zelven .... Ik ben schuldig de Synode te zeggen, dat mijne wetenschappelijke kennis niet toereikend is tot dat gewigtig en veel omvattend werk. Met het oog op mij zelven zoude ik dus plechtig moeten bedanken .... Dan, zie ik op de algemeene begeerte der Kerk, die met zooveel liefde en vertrouwen mij is gebleken en op het anders dierbaar en heerlijk werk, dan geef ik mij over aan de dienst der Kerk, ook in dezen met al mijne kracht en met allen lust. ... Mogt ik reeds meermalen zeggen, bij gewigtige roepingen in de Kerk: ,Heere zie hier ben ik.' Dat doe ik nu ook in dezen met eene volkomene overgave mijns harten" (Acta, Sinode 1869, art. 61).

$\mathrm{Na}$ die reorganisasie van 1876 is ' $\mathrm{n}$ nuwe verkiesing gehou. Die drietal was: Ds. D. Postma, prof. S. van Velzen van Kampen (Nederland) en prof. H. de Cock (ook van Kampen). Hoe groot die agting en liefde 
van die Kerk teenoor die stigter daarvan was, blyk uit die uitslag van die verkiesing: Ds. Postma 39, prof. Van Velzen, 2, prof. H. de Cock, 5.

Ten spyte van die geweldige meerderheid bedank ds. Postma tog vir die beroeping. In sy verklaring kom die volgende woorde voor: „Waarlijk, lieve Broeders, ik was en ben maar een noodhulp voor u geweest. Maar nu, dunkt mij, is de tijd gekomen, dat gij-ontwikkeld in kracht en reeds zoo goed georganiseerd-verplicht zijt de Theologische School nu ook zoo in te richten en van zoodanige professoren te voorzien als de tijd vereischt." (Acta 1876, bijlage 6).

Die Sinode het die bedanking met leedwese aanvaar en besluit om die beroeping van 'n professor tot die volgende vergadering uit te stel. Hier is die kerkvader weer met byna algemene stemme gekies en hoewel hy nog bedenkinge koester, laat hy hom die benoeming welgeval.

2. PROF. J. LION CACHET.

Gebore in Nederland, het Jan Lion Cachet aan 'n Christelike skool aldaar sy opleiding gehad. As jongeling is hy besiel deur Da Costa en ander wat dit opgeneem het vir die saak van die Here in 'n tyd toe die geestelike lewe grootliks versteen was.

Hoewel sy ouers van Joodse afkoms was, het hulle onder invloed van Da Costa tot die Christendom oorgegaan en prof. Cachet het dit gedoen met volle oortuiging van die hart.

As jongeling het hy na Suid-Afrika gekom en was eers in Natal werksaam onder die Voortrekkers as onderwyser en godsdiensoefenaar. Hier het hy saam met die Voortrekkers geesdriftig gewerk. Altyd was sy stryd 'n stryd vir die eer van God.

As hy leerling van vader Postma word, merk laasgenoemde dadelik sy besondere gawes op. Spoedig het geblyk dat hy nie alleen 'n uitnemende herder sou wees nie, maar ook 'n bekwame teoloog. Deur selfstudie het hy sy kennis geweldig verbreed en verdiep. Daarby was hy 'n man van lewensnysheid en mettertyd het hy die raadgewer van almal geword. By sy teraardebestelling is die volgende woorde gebesig: „Prof. Cachet was een groot man. Tegenover hem stonden wij als personen tegenover een grote persoonlikheid. Hij was 'n geniale man, van Zuid-Afrikaansche vermaardheid. Zijn raad gold bij ons, en het gewicht van zijn persoonlikheid gold nog sterker. Dit hebben wij, die met hem zijn omgegaan, diep gevoeld. In deze laatste dagen is het, als het ware, of de loop der dingen is gaan stilstaan met de dood van prof. Cachet. Wij zijn gelijk pelgrims, die op een kruispunt gekomen, niet weten waarheen. Wij vragen naar de weg en zijn stem zwijgt. Prof. Cachet was bij ons een wegwijzer."

Bij dieselfde geleentheid getuig die Vise-Konsul van die Nederlande, mnr. H. Altmann, onder meer: „Wat heeft hem zoo dierbaar gemaakt aan 
ons allen? Wat was de karaktertrek in hem, die ons zoo aantrok? lk geloof te mogen zeggen, zijn eenvoud. Wars van alle ijdel vertoon, nooit zich verhoogvaardigend op zijn ervaring en kennis, steeds eigen persoon wegcijferend voor de zaak."

Aangaande sy liefde vir die Teol. Skool word in Die Kerkblad van 1 Oktober 1912 getuig: "

„Een kwart eeuw bracht hij aan de school door en geen wonder dat men hem dikwels hoorde spreken van de Theol. School als ,zijn kind.' Als een vader beminde hij haar en waakte voor hare belangen. Wilde men de oude professor in vuur zien geraken dan moest men zijn school aantasten. Hij had fijne voelhorens voor die inrichting en bespiedde dikwels reeds van verre een gevaar dat bij anderen onopgemerkt bleef."

Toe aan hom in 1909 deur Koningin Wilhelmina die Offisierskruis in die Orde Oranje-Nassau aangebied is, het hy geantwoord: „Ik gevoel mij klein bij deze zaak, gedenkende loe ik in 1865 als onbekende jongeling te Rustenburg kwam. Bij dit eerbewijs buig ik mij nederig voor mijn God, die mij dit deed genieten."

Tereg kon dr. S. O. Los by sy afsterwe opmerk: „Met prof. Cachet is een periode van de Geref. Kerk van Zuid-Afrika afgesloten. Met hem is de „Sturm-und-Drang"-periode der Kerk geëindigd. Vaders Postma en Cachet hebben gestreden. Paulus heeft geplant, Apollos heeft natgemaakt. God heeft de wasdom gegeven. Deze Apollos is nu heengegaan, naar de heerlikheìd zijns Gods. Daarom moeten wij de dooden loslaten. Zij horen bij Christus. Maar gedenkt hem en zegt: ,Zie, hier ben ik, Heere, bij het graf van Cachet. En ik zweer een dure eed, dat mijn goed, en mijn vlees, en mijn bloed, zijn voor uwe heilige zaak, O Heere, God onzer vaderen.'"

Mag die lewenswandel van hierdie twee diensknegte van Christus vir ons van die jonger geslag altyd 'n voorbeeld bly.

DIE REORGANISASIE VAN 1876.

Spoedig het geblyk dat 'n voltydse professor nodig sal wees om volle reg aan die teologiese opleiding te laat geskied en dat naas hom 'n voltydse dosent moet wees vir die voorbereidende wetenskappe. Hierdie stap is dan ook gedoen deur die sinode van 1876. In verband met die dosent .vir die voorbereidende wetenskappe is bepaal dat hy nie 'n minder graad as B.A. moet besit nie. Tot professor theologicus is ds. D. Postma gekies en tot professor litterarum sy seun, die heer P. Postma, B.A. In 1880 is prof. P. Postma, intussen tot proponent hevorder, beroep tot herder ell leraar van die gemeente Burgersdorp, waarop sy broer, die heer M. Postma, B.A., tot professor beroep is. Hy het tot 1889 aan die skool gearbei en in hierdie tyd was daar gedurig vooruitgang. Studente is selfs vir die 
B.A. graad opgelei. Tot aan die Engelse oorlog het ook die here $S$. Postma, B.A., J. A. du Plessis, B.A., P. C. Snyman, B.A. en D. Postma, B.A., gedurende sekere tydperke die voorbereidende vakke behartig. 'n Mens kan nie anders nie as om eerbied te hê vir die arbeid wat onder sulke moeilike omstandighede gedoen is.

\section{GEDURENDE DIE GOUDOORLOG.}

1 Vir die beginsel waarvoor dit staan, moes die Teologiese Skool al baie verduur. So was dit ook gedurende die Engelse oorlog van 1899-1902. Menigmaal het dit in diê kommervolle tyd gelyk of die Skool sou ondergaan, maar--Gode die dank-ná die oorlog sou dit in 'n heeltemal nuwe gedaante verskyn.

Die studente van O.V.S. en Transvaal het direk by hul kommando's gaan aansluit. Vanaf November 1899 tot April 1900 is die skool gesluit en die twee literariese' professore trek uit saam met 'n aantal studente, om nuttige dienste in die ambulans te verrig. Prof. Cachet is op 5 Maart 1901 gearresteer op aanklag van hoogverraad en moes ses weke in die gevangenis deurbring. Die student (later ds.) W. J. de Klerk is aangesê om na Kingwilliamstown te vertrek waar hy enkele maande moes vertoef. Sowel die professor as sy student is later weer vrygelaat. 'n Vyftal studente het gedurende die oorlog hul lewe gegee ,vir vryheid en reg" soos die opskrif lui op die monument wat tot hulle nagedagtenis opgerig is en voor die gebou van die Teologiese Skool staan.

OORPLASING VAN DIE SKOOL NA POTCHEFSTROOM IN 1905.

Reeds vroeër het stemme opgegaan vir die verplasing van die Skool na die Suid-Afrikaanse Republiek, veral omdat die Hollandse taal daar sy regte plek in die skoolwese ingeneem het. Dic kerk het gevoel dat die Skool in die Engelse kader waarin dit te Burgersdorp noodwendig moes verkeer, sy beginsels nie tot kragdadige openbaring kon laat kom nie. Op die sinode van 1894 is reeds beskrywingspunte behandel wat gevra het dat die Skool na Transvaal verplaas sal word. On verskillende redes kon die sinode egter hieraan geen gevolg gee nie. Belangrik is dat toe reeds besluit is om die literariese afdeling te splits in 'n laere en 'n hoëre afdeling. Doel was dat die laere afdeling later sou ontwikkel tot 'n Gereformeerde Gimnasium, wat werklikheid geword het by die totstandkoming lan 'n inrigting met hierdie naam op Steynsburg.

Ná die Engelse oorlog het ds. P. Postma en dr. J. D. du Toit hulle beywer vir die insameling van fondse om die Skool na Potchefstroom te verplaas. $\mathrm{Na}$ 'n debat van drie dae het die Sinode van 1904 tot die verplasing besluit en in 1905 was reeds die skoolgebou, sowel as die woning van die professor theologicus gereed. 
Nou tree prof. dr. F. Postma as literariese professor op en later kom professore Duvenage en Kamp by. In 1910 ontvang prof. Cachet eervol ontslag en in sy plek word gekies dr. J. D. du Toit.

In 1914 is ' $n$ tweede teologiese professor gekies in die persoon van dr. S. O. Los en in 1925 volg die derde as dr. C. J. H. de Wet tot die geledere toetree. Dr. S. O. Los is opgevolg deur prof. J. A. du Plessis, wat gedurende 15 jaar sy beste kragte aan die inrigting gegee het. Oor die betekenis van die tans nog lewende professore wei ons tans nie verder uit nie, maar ons oorsig sou onvolledig wees as ons nie die betekenis van die arbeid van wyle prof. J. A. du Plessis in dankbare herinnering bring nie. Die hooggeagte ontslape professor het die Teologiese Skool en die Gereformeerde Kerk innig liefgehad en altyd in die bres getree wanneer die goeie naam van Kerk en'Skool aangetas is. Wanneer hy op meerdere vergaderinge opgetree het, kon elkeen voel dat hy deeglik op hoogte was van kerkregtelike vraagstukke. Sy frisse artikels in Die Kerkblad het altyd aandag getrek. Vir die totstandkoming van die teenwoordige geboue was prof. du Plessis grootliks verantwoordelik en die spore van sy arbeid kan nog duidelik in biblioteek en argief gesien word. Ons dank die Here vir die kostelike gawes wat hy aan ons Skool en prof. du Plessis geskenk het. Sy arbeid is van blywende betekenis.

- $\mathrm{Na}$ die plotselinge oorlyde van prof. du Plessis in 1935 is skrywer hiervan gekies.

'n Groot aantal predikante het aan die Teol. Skool hul opleiding ontvang. Die betekenis van die Skool word eers dan na waarde geskat as bedink word wat elkeen van hierdie kragte beteken het. lemand wat besel wat die magtige betekenis van die prediking is, weet ook watter ewigheidswaarde 'n Teologiese Skool het.

DIE TOEKOMS.

Ons van die jonger geslag besef die groot verantwoordelikheid wat op ons rus. Menigeen vra: „sal die geslag van die toekoms die pand wat aan hulle toevertrou is, veilig bewaar of sal daar verwatering wees?" Ons weet dat ons feilbare mense is, maar ons wil by hierdie driekwarteeufees aan die ou garde die plegtige versekering gee dat ons met die hulp van die Here wil voortbou-soos die stigter van die kerk dit genoem het-op „Gereformeerde, dit is op Bybelse grondslae." Ons leuse sal altyd wees die sinspreuk van die Teologiese Skool: „U LIG EN U WAARHEID."

Potchefstroom.

S. DU TOIT. 